\title{
MBD Attributes Template Method of Aeronautical Products
}

\author{
Xiumao Yang ${ }^{1}$, Zhengliang $\mathrm{Wu}^{1}$, Yongzhu $\mathrm{Hou}^{2}$, and Jihong Liu ${ }^{2, *}$ \\ ${ }^{1}$ Hongdu Group Company of Aeronautical Industry, 330024 Nanchang, China \\ ${ }^{2}$ School of Mechanical Engineering and Automation, Beihang Uiversity, 100191 Beijing, China
}

\begin{abstract}
Model-based Definition (MBD) expresses the technical information of traditional engineering drawings in a three-dimensional environment. The formed MBD dataset completely express the product information, what changed the product development model and improved product development efficiency. However, the integrity of the MBD dataset is difficult to guarantee and the efficiency to build it is low. In order to solve this problem, this paper proposes to use MBD attributes template method to solve the generation problem of attributes information in MBD dataset. Firstly, the concept and connotation of MBD attributes and MBD attributes template are described. Secondly, the type of aeronautical products and MBD attributes are combed to form MBD attributes template for different types of products. Thirdly, the process of MBD attributes template method is proposed. Finally, the validity of the proposed method is verified by the MBD attributes template construction and attributes values filling of a forging part. The results show that MBD attributes template method not only improves the efficiency of MBD attributes generation, but also improves the integrity and accuracy of MBD dataset.
\end{abstract}

\section{Introduction}

Three-dimensional model plays a vital role in engineering domain. It can drive product design, manufacturing, assembly and inspection stage of production development directly. The Model-based Definition (MBD) technology is proposed by the American Society of Mechanical Engineers based on its digital product definition specification (ASME Y14.412003) and combined with its digital manufacturing experiences [1]. MBD technology express technical information in the three-dimensional model, forming a completed product model drive product development activities, is a current research focus. For example: MBD design under the product lifecycle scenario [2]; through the MBD dataset to assist the construction of the MBD process model [3]; multi-level structured MBD model support the mechanical parts reuse [4].

MBD has been widely used in the whole aeronautical field. MBD-based 3D design has become the main development model of the current aeronautical enterprises. However, there are still has many management problems and technical problems need to be solved [5], including how to improve the efficiency of MBD dataset construction and ensure the integrity and accuracy of the MBD dataset.

In view of this problem, [6] studied the automatic annotation technology of $3 \mathrm{D}$ model based on $\mathrm{GB} / \mathrm{T}$ 24734 to improve the efficiency of 3D model annotation. However, the MBD dataset contains MBD attributes besides annotation. MBD attributes contains both the management information needed for other product development phases and the technology information used to assist the MBD annotation to completely defining the product model. The attributes is of a wide variety and its account is large, thus: 1) there is incomplete problem when designers add MBD attributes, and is not conducive to management; 2) designers need to consult the relevant manual and standard to add MBD attributes what is time-consuming and laborious. In this paper, MBD attributes template method is proposed to solve the problem of MBD attributes generation. By combing the types of products and MBD attribute types, the MBD attributes template is formed according to different products types. And the MBD attributes values are itemized to support the construction of MBD attributes fast and accurate.

\section{MBD attributes}

MBD technology expresses the technical information in a three-dimensional environment, forming the MBD dataset that can fully describe the product. Technology information includes geometric dimensions and tolerances, roughness, datum, and other technical requirements once in the two-dimensional drawings. The physical form of MBD dataset is MBD model, which essence is adding the technical information to the threedimensional model.

The ASME Y14.41-2003 standard specifies the contents of the MBD model firstly. As shown in Figure 1, the MBD dataset includes three parts: design model, annotation and attributes. The design model is the traditional meaning of the three-dimensional model which is consists of model geometry and supplemental

Corresponding author: ryukeiko@buaa.edu.cn 
geometry; Annotation is one type of technology information which is visible in the model of various dimensions and tolerances, roughness, datum and other content. They do not need to query or do other operations of the model. Attributes is other information which used to complete the definition of the product. The content of attributes is not visible in the model, but can be obtained through querying the product model.

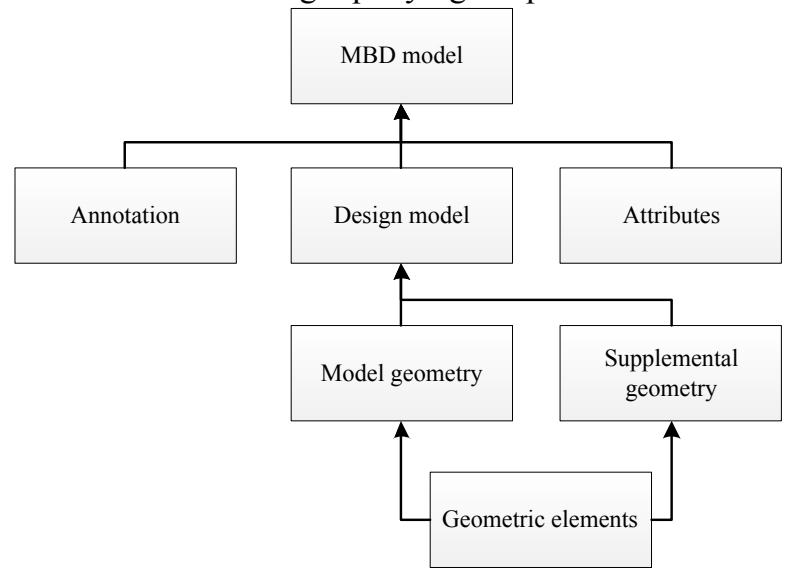

Fig. 1. Contents of MBD model.

In engineering practice, the implementation of MBDbased 3D design not only considering the integrity of the definition of product dataset, but also need to consider the collaborative of design and manufacture, modelbased product lifecycle management and other factors. In this situation, it requires the attributes of MBD model both supplement the content of the annotation and include some basic information and a part of the management information of other development stage. In addition, engineering design is a process of repeated iterations and constantly validate, so the information that can be processed and obtained at different design stages is not the same. In the field of aviation, the design and manufacture of aircraft introduced the concept of maturity to describe the different stage of the parts design. After the previous stage is completed, the product design can enter a new stage of maturity. The maturity of product digital design usually divided into three stages: M0, M1 and M2.

In this paper, the MBD attributes is defined as the attributes of the MBD model which contains the technical information needed to design and manufacturing process and the management information in the product development process. This information needs to be defined in different maturity stages such as M0, M1 and M2.

In this paper, we use MBD attribute template to determine the MBD attributes content required by the different types of products. The MBD attributes content will be standardized, itemized and regularized in order to improve the MBD model design efficiency and the integrity and accuracy of MBD attributes.

MBD attributes template has two advantages:

(1) Build a unified MBD attributes template for different types of products. The designers no longer need to consider what attributes should to be added. They can just follow the template to fill in the contents according to the attributes template;

(2) For the attributes that can form a set of rules, the designer can directly select the corresponding attributes values rather than through their own search and entry.

\section{Classification of products and MBD attributes}

To achieve the MBD attributes template method we should firstly divided the type of products and MBD attributes. The classification of products is in order to distinguish the characteristics of different types of Aeronautical products, which is the basis of constructing different MBD attributes template. The classification of MBD attributes is to sort out the management information and technical information of aviation business needs and complete the MBD model content.

\subsection{Classification of Products}

The aeronautical products include eight types: part, assembly, piping, harness, deformer, virtual part, overall model and finished product. Each category can continue to be divided into multiple subtypes. The division of each category and its meaning are shown in Table 1.

Table 1. Classification of Products.

\begin{tabular}{|c|c|c|}
\hline Type & Subtype & Meaning \\
\hline Part & $\begin{array}{l}\text { Sheet metal, } \\
\text { Machine part, } \\
\text { Forging part, } \\
\text { Casting part, } \\
\text { Welding part, } \\
\text { Composite } \\
\text { material part } \\
\text {.et al }\end{array}$ & $\begin{array}{l}\text { The design } \\
\text { unit which } \\
\text { constitute the } \\
\text { assembly }\end{array}$ \\
\hline Assembly & $\begin{array}{l}\text { Riveting assembly, } \\
\text { Clamp assembly, } \\
\text { Welding assembly } \\
\text { et al }\end{array}$ & $\begin{array}{l}\text { Composed of } \\
\text { parts, usually } \\
\text { as a system or } \\
\text { subsystem }\end{array}$ \\
\hline Piping & $\begin{array}{l}\text { Tube, Conduit } \\
\text { assembly }\end{array}$ & $\begin{array}{l}\text { A component } \\
\text { of one or } \\
\text { more tubes }\end{array}$ \\
\hline Harness & $\begin{array}{c}\text { Geometric } \\
\text { harness, Two - } \\
\text { dimensional wire } \\
\text { harness, } \\
\text { Circuit diagram, } \\
\text { et al }\end{array}$ & $\begin{array}{l}\text { The wiring } \\
\text { parts used to } \\
\text { connect the } \\
\text { different parts }\end{array}$ \\
\hline Deformer & $\begin{array}{c}\text { Part deformation, } \\
\text { Standard part } \\
\text { deformation, } \\
\text {.et al }\end{array}$ & $\begin{array}{l}\text { Obtained } \\
\text { through the } \\
\text { deformation } \\
\text { design by } \\
\text { other types of } \\
\text { products }\end{array}$ \\
\hline Virtual Part & $\begin{array}{c}\text { Fastener assembly, } \\
\text { Annotation model, } \\
\text { Catheter package } \\
\text { model } \\
\text { et al }\end{array}$ & $\begin{array}{l}\text { In the form of } \\
\text { a geometric } \\
\text { graph set, } \\
\text { without a } \\
\text { solid model }\end{array}$ \\
\hline
\end{tabular}




\begin{tabular}{|c|c|c|} 
Overall & $\begin{array}{c}\text { Overall skeleton } \\
\text { model, Theoretical } \\
\text { shape model, } \\
\text { Aircraft } \\
\text { benchmark model, } \\
\text { et al }\end{array}$ & $\begin{array}{c}\text { Used to } \\
\text { control the } \\
\text { design range } \\
\text { of system, } \\
\text { sub-system }\end{array}$ \\
\hline $\begin{array}{c}\text { Finished } \\
\text { Product }\end{array}$ & -- & $\begin{array}{c}\text { The final } \\
\text { delivery of the } \\
\text { design }\end{array}$ \\
\hline
\end{tabular}

\subsection{Classification of MBD attributes}

As with the division of products type, the MBD attributes can be divided into multiple types, each of which contains multiple subtypes. Table 2 lists the types and subtypes of the MBD attributes of the aeronautical products, and the maturity level that should be generated for each subtype attribute value. It should be noted that: 1) different subtypes of the same type may belong to different maturity stages, such as the material grade belongs to the M0 stage but the wool size belongs to the M1 stage, even though they both belongs material description type; 2) most of the technical information contained in MBD attributes exist in subtype general notes of the product notes, including manufacturing and inspection basis, heat treatment, surface treatment, nondestructive testing methods, sharp edge chamfering, inspection location, machining requirements, and so on.

Table 2. Classification of MBD attributes.

\begin{tabular}{|c|c|c|}
\hline Type & Subtype & $\begin{array}{c}\text { Maturity } \\
\text { Stage }\end{array}$ \\
\hline $\begin{array}{l}\text { Security } \\
\text { Description }\end{array}$ & $\begin{array}{l}\text { Security Level } \\
\text { Time Limit }\end{array}$ & $\begin{array}{l}\text { M0 } \\
\text { M0 }\end{array}$ \\
\hline $\begin{array}{l}\text { Standard } \\
\text { Annotation }\end{array}$ & $\begin{array}{c}\text { Weight Unit } \\
\text { Length Unit } \\
\text { Copyright Notice }\end{array}$ & $\begin{array}{l}\text { Automatic } \\
\text { Generated }\end{array}$ \\
\hline $\begin{array}{c}\text { Product } \\
\text { Description }\end{array}$ & $\begin{array}{c}\text { Product ID } \\
\text { Product Type } \\
\text { Product Subtype } \\
\text { Supply Characteristics } \\
\text { Symmetrical or Not } \\
\text { Symmetrical Description }\end{array}$ & $\begin{array}{l}\text { M0 } \\
\text { M0 } \\
\text { M0 } \\
\text { M0 } \\
\text { M1 } \\
\text { M1 }\end{array}$ \\
\hline $\begin{array}{l}\text { Material } \\
\text { Description }\end{array}$ & $\begin{array}{l}\text { Material Grade } \\
\text { Wool Size }\end{array}$ & $\begin{array}{l}\text { M1 } \\
\text { M2 }\end{array}$ \\
\hline $\begin{array}{l}\text { Design } \\
\text { Basis }\end{array}$ & $\begin{array}{l}\text { Theoretical Shape } \\
\text { Theoretical Circle } \\
\text { Design Suggestions }\end{array}$ & $\begin{array}{l}\text { M1 } \\
\text { M1 } \\
\text { M1 } \\
\end{array}$ \\
\hline $\begin{array}{l}\text { Product } \\
\text { Version }\end{array}$ & Development Stage & M0 \\
\hline $\begin{array}{l}\text { Product } \\
\text { Characterist } \\
\quad \text { ics }\end{array}$ & $\begin{array}{c}\text { Single Element Type } \\
\text { Long Period or Not } \\
\text { Important Parts Amount } \\
\text { Key Parts Amount }\end{array}$ & $\begin{array}{l}\text { M1 } \\
\text { M1 } \\
\text { M2 } \\
\text { M2 }\end{array}$ \\
\hline $\begin{array}{l}\text { External } \\
\text { Reference }\end{array}$ & - - & M1 \\
\hline $\begin{array}{l}\text { Auxiliary } \\
\text { Geometry }\end{array}$ & - & M1 \\
\hline $\begin{array}{l}\text { Product } \\
\text { Notes }\end{array}$ & $\begin{array}{c}\text { General Notes } \\
\text { Structural Elements }\end{array}$ & $\begin{array}{l}\text { M1 } \\
\text { M1 }\end{array}$ \\
\hline
\end{tabular}

\begin{tabular}{|c|c|c|}
\hline & Wool Model & M2 \\
\hline $\begin{array}{c}\text { Link } \\
\text { Definition }\end{array}$ & - & M1 \\
\hline Weight & $\begin{array}{c}\text { Theoretical Weight } \\
\text { Model Weight }\end{array}$ & M2 \\
& M2 \\
\hline
\end{tabular}

\section{MBD attributes template method}

As showed in Figure 2, the MBD attributes template method consists of six steps:

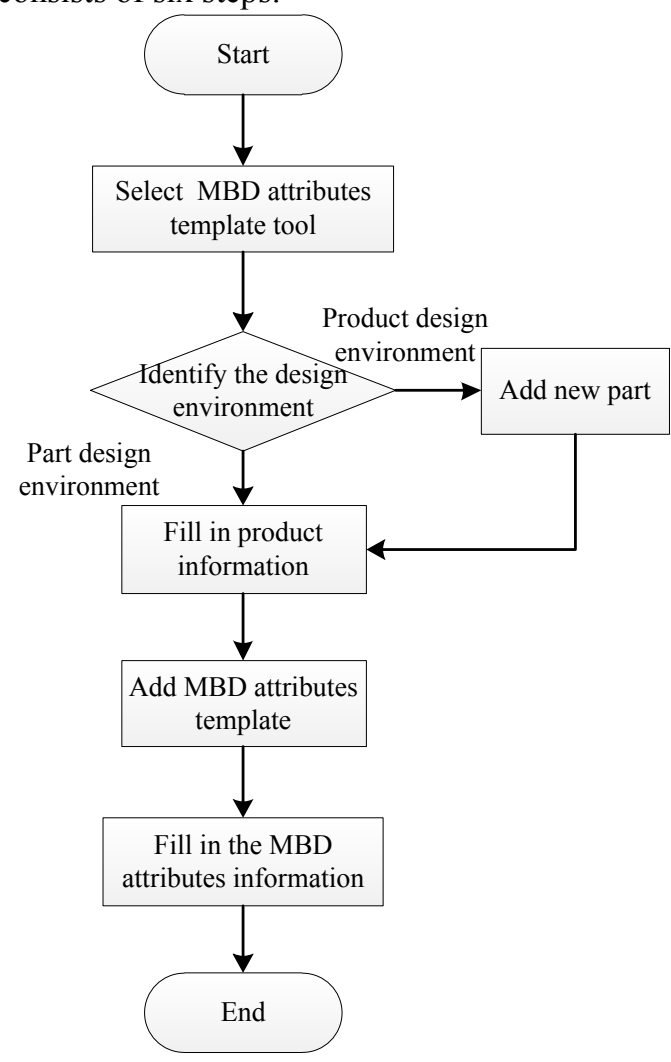

Fig. 2. MBD attributes template method.

Step 1: Select MBD attributes template tool: During the product design process, the MBD attributes template method is executed by the custom MBD attributes template tool;

Step 2: Identify the design environment: Automatically identify the current design environment, which mainly including product design environment and part design environment. Each type of design environment should have different MBD attributes template process. If the current design environment is product design environment, then the user needs to add a new part and build its MBD attribute template, go to step 3 ; if the current design environment is part design environment, then the user needs to directly build the corresponding MBD attributes template of the current part, go to step 4;

Step 3: Add new part: Create a new part in the product design environment automatically;

Step 4: Fill in product information: fill in the part type, subtype and part ID of the product will be created; 
Step 5: Add MBD attributes template: Automatically find the corresponding MBD attributes template according to the filled part information and express the template in the product structure tree in a structured way;

Step 6: Fill in the MBD attributes information: Fill in the values of the various types of MBD attributes in the template based on the added MBD attribute template. The attributes values are filled in three ways: automatic creation of attribute values, selection of attribute value entries and manual entry.

\section{Validation}

In this paper, the MBD model of a forging part is used to illustrate the MBD attributes template method. This article use the VB language and VBScript language to achieve the development of MBD attributes template tool based on the CATIA platform, and through the CATIA macro function to provide custom MBD attributes template tool bar. As shown in Figure 3, MBD attributes template tool bar contains two functions: 1) create MBD attributes template; 2) fill in MBD attributes values.

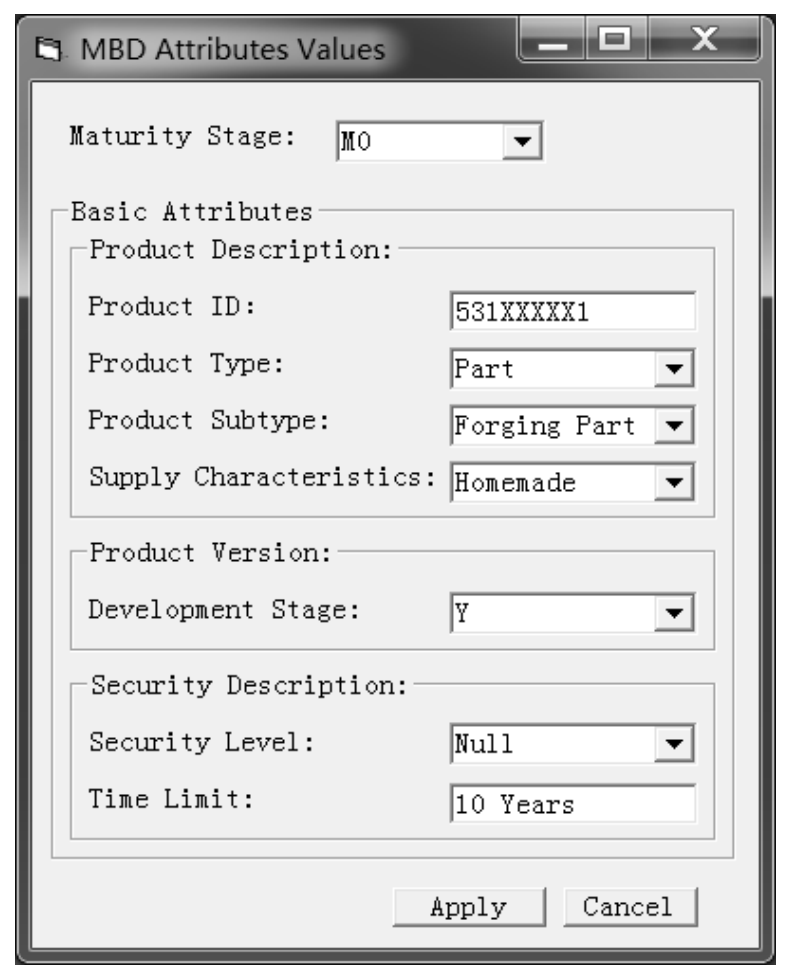

Fig. 4. Fill in MBD attributes values.

Firstly, enter the MBD attributes template creation interface through the button shown in Figure 3 marked (1). At the same time, the system automatically detects the current design environment is product design environment and requires users to fill in product-related information. When the user completes the information such as product ID, product type and product subtype, they can construct the relevant MBD attributes in the product structure tree automatically by clicking the "Apply" button.

After completing the creation of MBD attributes template, user can enter the MBD attributes value filling interface shown in Figure 4 by clicking the button shown in Figure 3 marked (2). The user needs to specify the stage of the current product design first (M0 stage in the Figure 4) before the MBD attributes value is filled in. After selecting the corresponding maturity stage, the system will loading the MBD attributes required for this phase. The user can check or fill in the relevant attributes value according to the given template. If all the attributes values are completed, the system updates the attributes values to the product structure tree.

When the product design completed the M0 stage, the user can continue to fill the MBD attributes values of other maturity stage such as M1 and M2 by the function of Filling MBD attributes values and ultimately complete the product design.

\section{Conclusion}

MBD technology brings both convenience and challenges to engineering design and manufacturing. How to construct MBD model accurately and rapidly is an essential engineering problem needed to be solve. This paper proposed the MBD attributes template method, and form different MBD attributes template for different product types by combing the aeronautical products and MBD attributes types. The MBD attributes template can constructed in a more completely and fast way. In addition, the article formed the MBD attributes values rules that can be formed. The designer can directly select the attributes values, thus reducing the workload of the designer, and improving the efficiency and accuracy of the MBD attributes. In fact, the MBD model also contains annotation information besides MBD attributes, which will be the focus of our future work.

\section{Acknowledgements}

This work has been supported by Project of National Key Technology R\&D Program through approval No. 2015BAF17B01.

\section{References}

1. LIU J H., SUN L S, ZAHNG X, et al. Connotation and key problem of three-dimensional digital. Computer Integrated Manufacturing Systems, 20(3): 494-504 (2014)

2. Alemanni M, Destefanis F, Vezzetti E. Model-based definition design in the product lifecycle management scenario. International Journal of Advanced Manufacturing Technology, 52(1-4): 114(2011)

3. Wan N, Mo R, Liu L, et al. New methods of creating MBD process model: On the basis of 
machining knowledge. Computers in Industry, 65(4): 537-549(2014)

4. Huang $\mathrm{R}$, Zhang S, Bai X, et al. Multi-level structuralized model-based definition model based on machining features for manufacturing reuse of mechanical parts. International Journal of Advanced Manufacturing Technology, 75(5-8): 1035 1048(2014)

5. Quintana V, Rivest L, Pellerin R, et al. Will Modelbased Definition replace engineering drawings throughout the product lifecycle? A global perspective from aerospace industry. Computers in Industry, 61(5): 497-508(2010)

6. An H, Yan G R, Lei Y. Automatic dimensioning of 3D model based on GB/T 24734. Journal of Beijing University of Aeronautics and Astronautics, 38(3): 416-421(2012)

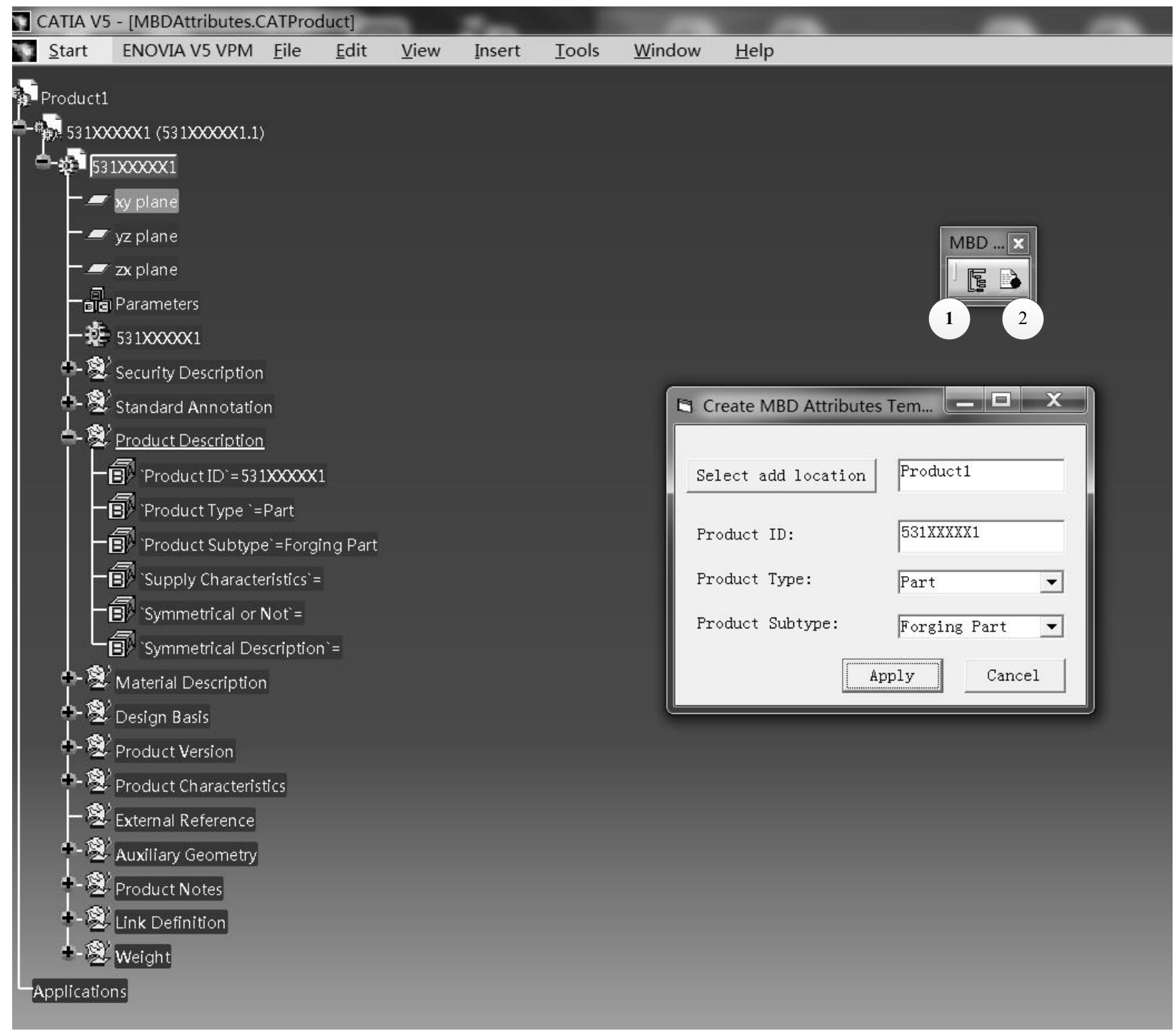

Fig. 3. Create MBD attributes template. 